REVISTA X, Curitiba, volume 12, n.2,p.130-150,2017

\title{
O PORTUGUÊS COMO SEGUNDA LÍNGUA DOS SURDOS BRASILEIROS: UMA APRESENTAÇÃO PANORÂMICA
}

\author{
Portuguese as a Second Language for Deaf Brazilians: a Panoramic View
}

\author{
Giselli Mara da SILVA - FALE-UFMG ${ }^{1}$
}

\begin{abstract}
RESUMO: Neste artigo, pretende-se apresentar e discutir, de forma panorâmica, questões pertinentes à situação dos surdos brasileiros como aprendizes e usuários de português como segunda língua (PL2). O trabalho dialoga com estudos sobre o bilinguismo e a educação bilíngue dos surdos e sobre os processos de aquisição e de ensino-aprendizagem de PL2, no caso desse grupo. Destaca-se a importância da educação bilíngue como proposta adequada às necessidades linguísticas da comunidade surda, como minoria linguística, já que visa garantir o acesso pleno à Libras como primeira língua e ao PL2. No que tange especificamente à condição dos surdos como usuários e aprendizes de PL2, ressaltam-se: (i) as necessidades desses aprendizes, tais como o uso do português escrito em várias esferas sociais; (ii) as semelhanças dos surdos com outros aprendizes de PL2; e (iii) as especificidades dos aprendizes surdos. Finalmente, destacam-se as especificidades dos surdos no que tange à apreensão visual da língua escrita, a mediação da Libras na aprendizagem de PL2 bem como as características da escrita da pessoa surda e a importância de uma avaliação coerente.
\end{abstract}

PALAVRAS-CHAVE: português como segunda língua; surdos; Libras; educação bilíngue.

ABSTRACT: This article aims to present and discuss, in a panoramic view, issues related to the situation of deaf Brazilians while learners and users of Portuguese as a second language (PSL). The work discusses studies about bilingualism and the bilingual education of the deaf and about the acquisition and the teaching-learning processes of PSL in this group. Particular attention is brought to the importance of a bilingual education as an adequate proposal for the deaf community linguistic needs. Regarding the deaf people's condition as users and learners of PSL, it is relevant to highlight: (i) the needs of these learners, such as the use of written Portuguese in various social spheres; (ii) the similarities between the deaf and other learners of PSL; and (iii) the specificities of deaf learners. Finally, it is emphasized that the deaf people's specificities in relation to the visual apprehension of the written language, the mediation of Libras in the learning of PSL, as well as the writing characteristics of the deaf person and the importance of a cohesive evaluation.

KEY-WORDS: Portuguese as second language; deaf people; Libras; bilingual education.

\footnotetext{
${ }^{1}$ Graduada em Letras, mestre em Educação e doutoranda em Estudos Linguísticos pela UFMG; docente da Faculdade de Letras da UFMG. Email
} 


\section{INTRODUÇÃO}

Recentemente, os surdos brasileiros conquistaram o reconhecimento legal da Língua de Sinais Brasileira (Libras) e, posteriormente, alguns direitos educacionais e linguísticos importantes (BRASIL, 2002; BRASIL, 2005). Dentre esses direitos, destacase o de aprender e usar o português como sua segunda língua (L2), o qual deve ser viabilizado por meio de inúmeras ações, como: a formação de professores, a avaliação diferenciada de textos escritos por esses indivíduos, etc.

Desta forma, neste artigo, pretende-se apresentar e discutir, de forma panorâmica, questões pertinentes à situação dos surdos brasileiros como aprendizes e usuários de português como segunda língua (PL2), bem como aspectos relativos a processos de ensino e de aprendizagem do português para/ por esse grupo. Serão abordadas então algumas questões gerais, tais como: o que significa dizer que o surdo aprende e usa o português como L2; quais são as características desses aprendizes e que implicações trazem para o ensino?; que estratégias didáticas são adequadas aos aprendizes surdos?.

Para abordar tais questões, este trabalho foi construído por meio de um diálogo com trabalhos da área de português para surdos no Brasil, bem como na área de bilinguismo dos surdos dentro e fora do Brasil. Para tanto, o texto está organizado da seguinte maneira: nesta introdução, faz-se uma breve contextualização do tema; na próxima seção, pretende-se apresentar a situação linguística dos surdos e as questões que envolvem o acesso às línguas; em seguida, faz-se uma apresentação geral da educação bilíngue para surdos e do ensino de PL2. Na seção maior do artigo, serão abordadas as necessidades e especificidades desses aprendizes e, finalmente, nas considerações finais, retomam-se alguns aspectos importantes no que tange às especificidades dos surdos $\mathrm{e}$ necessidades de avanços na área.

Apesar das especificidades desses aprendizes, o ensino de PL2 para surdos integra a área maior que compreende o ensino de português a falantes de outras línguas, inclusive com questões comuns a outros aprendizes, especialmente aqueles pertencentes a grupos minoritários. Assim, neste artigo, objetiva-se sistematizar algumas informações gerais sobre a área de PL2 para surdos, buscando apresentar informações básicas para os interessados nesse grupo de aprendizes. 
REVISTA X, Curitiba, volume 12, n.2,p.130-150,2017

\section{A SITUAÇÃO LINGUÍSTICA DOS SURDOS E O ACESSO ÀS LÍNGUAS}

As comunidades surdas vivem um tipo de bilinguismo de minoria em que se utiliza, no cotidiano, a língua de sinais (LS) local e a língua majoritária (GROSJEAN, 2008). Porém, diferente de outros grupos de bilíngues, o bilinguismo dos surdos não é determinado por questões de território, de imigração ou por opções individuais ou familiares; para a maioria dos surdos, que nascem em famílias ouvintes onde não se utiliza a LS, o bilinguismo vai depender de medidas apropriadas de suporte (PLAZA-PUST, 2014). Deste modo, diferente de outros grupos minoritários que geralmente adquirem a língua da casa como primeira língua (L1), a maioria dos surdos não encontrará em sua família a possibilidade de aquisição de uma língua “acessível” a eles ${ }^{2}$. Consequentemente, a aquisição da LS como L1 vai se dar de outras formas: (i) seja por meio da participação em projetos que visam à garantia do desenvolvimento linguístico e cognitivo da criança surda em idade pré-escolar, o que é muito raro no Brasil ${ }^{3}$; (ii) quando da entrada em escolas onde haja usuários da LS; (iii) ou mais tardiamente, no contato com surdos, em ambientes diversos e/ou nos espaços dos movimentos políticos de surdos.

Portanto, diferentemente das crianças ouvintes, para as crianças surdas a idade de início da exposição à sua L1, uma língua acessível, é bastante variável, dependendo de inúmeros fatores, como a idade de diagnóstico, a disponibilização de serviços, etc. (MAYBERRY, 2007). Em ampla pesquisa realizada com 101 surdos brasileiros, Quadros e Cruz (2011) encontraram surdos que iniciaram o processo de aquisição da Libras em diferentes períodos, a saber: 40 participantes iniciaram a aquisição antes dos 4 anos e 6 meses, 51, no período entre 4 anos e 7 meses e 9 anos; e 10 participantes, depois de 10 anos. Encontram-se, desta forma, surdos que viveram longos períodos de certo grau de

\footnotetext{
${ }^{2}$ Conforme Plaza-Pust (2012), as noções de L1 e língua materna são associadas a critérios de idade (primeira língua adquirida) e ambiente (a língua usada na casa), sendo assumido o pleno acesso à língua pela criança. Porém, no caso dos surdos, a "acessibilidade" torna-se um critério fundamental na definição de qual língua será considerada a L1, já que as pessoas surdas somente podem acessar plenamente e adquirir "naturalmente" as LS Assim, neste trabalho, usamos o termo L1 considerando o critério de acessibilidade.

${ }^{3}$ Diferente de países como a Suécia (AHLGREN, 1994 apud QUADROS, 1997a) e os Estados Unidos (HOFFMEISTER, 1999), onde foram desenvolvidos programas de atendimento às crianças surdas e de apoio a suas famílias; no Brasil, o que ocorre é o atendimento a crianças surdas em escolas especiais ou especializadas que, em alguns casos, oferecem cursos de Libras para os pais. Porém, não há, até onde vai nosso conhecimento, programas mais amplos e sistemáticos de acompanhamento das crianças surdas antes de idade escolar.
} 
privação linguística, situação que terá impacto em vários níveis de desenvolvimento desses indivíduos e também na aprendizagem de outras línguas.

Considerando a importância da aquisição da linguagem pelas crianças surdas em tempo e condições ideais, várias pesquisas têm sido conduzidas no sentido de mostrar que o bilinguismo é a opção ideal para essas crianças. Os estudos que investigam surdos filhos de surdos concluem que o desenvolvimento das crianças é comparável ao de crianças ouvintes, o que se constitui como uma forte evidência a favor do bilinguismo para as pessoas surdas ${ }^{4}$. Além disso, estudos têm mostrando as vantagens do bilinguismo para as pessoas surdas, evidenciando a relação positiva entre habilidades desenvolvidas na LS e habilidades na língua majoritária (ver, por exemplo, MAYBERRY, 2007; HOFFMEISTER, 2000).

Devido ao impedimento auditivo, os surdos não poderão adquirir a língua majoritária em interações face a face, dependendo de uma situação formal para ter acesso a essa língua. Desta forma, estando sujeita a uma série de fatores, tais como as escolhas da família, a disponibilidade de serviços, entre outros, a aprendizagem da língua majoritária poderá se iniciar por meio do tratamento fonoaudiológico, com foco na língua falada, ou por meio do processo de alfabetização, com foco na língua escrita.

No que tange à aprendizagem da língua escrita, há um consenso a respeito da possibilidade de o surdo aprender diretamente a língua escrita como L2, sem necessariamente utilizar a língua falada; porém, há pouco consenso sobre a possibilidade de a criança compensar a lacuna do acesso à língua falada tomando outros caminhos na aprendizagem da escrita e adquirindo com sucesso a gramática da L2 (PLAZA-PUST, 2012). De modo geral, os pesquisadores brasileiros que defendem a educação bilíngue para surdos assumem a importância do papel mediador da LS na aquisição da escrita e a relativa autonomia da língua escrita em relação à fala (ver, por exemplo, FERNANDES, 1999) ou ainda discutem as vantagens cognitivas para a criança surda do processo de alfabetização na escrita de sinais para um posterior processo de alfabetização na língua majoritária (ver, por exemplo, QUADROS, 1997b), o que detalharemos mais numa seção posterior sobre alfabetização.

\footnotetext{
4 "Estudos sobre crianças surdas, filhas de surdos, demonstram que estas apresentam desenvolvimento lingüístico, cognitivo e acadêmico comparáveis ao de crianças ouvintes, filhas de pais ouvintes, o que aponta para a importância de os surdos serem expostos à língua de sinais o mais cedo possível" (PEREIRA, 2002, p. 47).
} 
Atualmente no Brasil, alguns trabalhos (BOTELHO, 2002; S. SILVA, 2008; G. SILVA, 2010; I. SILVA, 2005) vão denunciar como os surdos apresentam baixos níveis de leitura e escrita do português, devido à insistência em modelos educacionais inadequados que focam no desenvolvimento do português oral em detrimento do acesso pleno e irrestrito à LS e do ensino adequado de PL2, desconsiderando assim a condição de minoria linguística dos surdos e suas potencialidades na aprendizagem visual das línguas.

Considerando, então, esse complexo contexto onde o acesso às línguas não é garantido às pessoas surdas, pode-se constatar como a educação precisa assumir um papel ainda mais proeminente e responder às necessidades linguísticas dos surdos (PLAZAPUST, 2012). Logo, nos últimos anos, tem-se intensificado no Brasil a luta da comunidade surda pela consolidação da educação bilíngue, com a proposta de implantação de escolas bilíngues para surdos ${ }^{5}$.

\section{EDUCAÇÃo bILÍngue E O ENSINO DE PORTUGUÊS COMO L2 PARA SURDOS}

A Educação Bilíngue para surdos é uma proposta educacional que começa a se difundir no Brasil principalmente a partir dos anos 1990 e propõe que se criem ambientes linguísticos favoráveis tanto à aquisição da Libras pelas crianças surdas, conforme o tempo de desenvolvimento linguístico esperado, como à aquisição do português como L2 (BRASIL, 2014; QUADROS, 1997a, entre outros). Essa proposta demanda a compreensão dos surdos como grupo social minoritário, usuário de outra língua, ou seja, exige que tenhamos uma perspectiva sócio-antropológica da surdez (SKLIAR, 1997). Dessa maneira, na proposta de educação bilíngue para surdos, o português figura como a L2 da pessoa surda, a ser ensinada por meio de metodologias específicas, considerandose as especificidades dos surdos em vários aspectos, sejam linguísticos, culturais, educacionais, etc.

Atualmente, os pesquisadores da área propõem que o ensino de português para surdos se baseie em concepções de língua que privilegiem a interação e o discurso (LODI

\footnotetext{
${ }^{5}$ Cabe destacar aqui o "Relatório sobre a Política Linguística de Educação Bilíngue - Língua Brasileira de Sinais e Língua Portuguesa" elaborado por um grupo de trabalho formado por pesquisadores surdos e ouvintes em que se explicitam as bases e os princípios da Educação Bilíngue para surdos (BRASIL, 2014).
} 
HARRISON, CAMPOS, 2002; PEREIRA, 2014; etc.), opondo-se à tradição estruturalista no ensino de línguas aos surdos, calcada na repetição de exercícios mecânicos. Nessa direção, destaca-se a publicação pelo Ministério da Educação de um livro voltado para a formação de professores de PL2 para surdos, no qual a abordagem interacionista no ensino de L2 é indicada aos professores (SALLES et al., 2004). O ensino de PL2 para surdos deve ser organizado em torno de dois eixos: uso da língua e reflexão sobre a língua e a linguagem (BRASIL, 1998, p.34-35), mas, no caso desses aprendizes, deve-se focar o uso da língua escrita, por meio da leitura e da produção de textos escritos ${ }^{6}$. O currículo de PL2 então vai se diferenciar ${ }^{7}$, já que o português figura como L2 para esse grupo, o qual é visto como um grupo linguístico minoritário, com cultura(s) própria(s).

Além de se considerar o ensino de L2 e de aspectos culturais da comunidade surda, o ensino dessa língua deve considerar o impedimento auditivo vivenciado por pessoas surdas, sendo que conteúdos curriculares voltados a aspectos fonético-fonológicos do português não devem ser contemplados ou, quando possível e necessário, deve haver adaptação das estratégias de ensino de forma a tornar acessível ao surdo tais conteúdos. Ainda cabe destacar que as aulas de PL2 devem ser ministradas em LS, tornando o conteúdo acessível ao surdo na língua de seu grupo sociocultural, o que discutiremos mais adiante.

Geralmente, a proposta de ensino de PL2 para surdos é efetivada em experiências de educação bilíngue no Brasil, ainda bastante incipientes e raras, mas que começam a ganhar força nos últimos $\operatorname{anos}^{8}$. Nessas experiências, o ensino de português ocorre geralmente em classes somente de alunos surdos, onde todos são aprendizes de português como L2 e compartilham a LS, principal língua das interações face a face. Essas classes de surdos, por sua vez, pertencem a escolas especiais ou escolas especializadas para

\footnotetext{
${ }^{6}$ Ver o exemplo citado por Silva (2005, p.111) de um programa voltado para surdos em que as atividades são divididas, conforme proposta de Geraldi (1984 apud SILVA, 2005) em: (i) Prática de Leitura de Textos; (ii) Práticas de Produção de Textos; (iii) Prática de Análise Linguística.

${ }^{7}$ Uma importante iniciativa de sistematização de sistematização de currículo de PL2 para surdos é o documento "Orientações Curriculares e Proposição de Expectativas de Aprendizagem para a Educação Infantil e Ensino Fundamental - Língua Portuguesa para a Pessoa Surda", Secretaria Municipal de Educação de São Paulo, elaborado e assessorado pela professora Maria Cristina da Cunha Pereira (SECRETARIA MUNICIPAL DE EDUCAÇÃO - SÃO PAULO, 2008).

${ }^{8}$ Podemos citar aqui algumas escolas consideradas escolas bilíngues para surdos: (1) Instituto Nacional de Educação de Surdos, no Rio de Janeiro; (2) Instituto Santa Terezinha em São Paulo; (3) Centro de Educação para Surdos Rio Branco, em São Paulo; (4) Escola Municipal Helen Keller, de Caxias do Sul; (5) Escola Municipal de Educação Bilíngue para Surdos Helen Keller, em São Paulo, entre outras.
} 
surdos ou mesmo a escolas comuns, onde se buscou contemplar a diferença linguísticocultural dos surdos por meio de projetos voltados a esses alunos.

Finalmente, cabe explicar que, para além dos problemas atuais que a educação brasileira já enfrenta, a proposta de Educação Bilíngue para surdos têm enfrentado desafios relacionados à falta de consciência da diferença linguística dos surdos. Destacase a implantação da proposta de inclusão educacional, que propõe que os surdos estudem em escolas comuns acompanhados por um intérprete de Libras-português. Para os movimentos políticos dos surdos brasileiros e para muitos pesquisadores, a inclusão dos surdos em escolas comuns, especialmente nos primeiros anos do Ensino Fundamental, não é uma proposta viável, já que essa educação supostamente "igualitária” apagaria a diferença linguística dos $\operatorname{surdos}^{9}$. Em escolas comuns, as crianças surdas geralmente enfrentam vários problemas na aquisição da LS pela falta de interação com outros surdos, colegas e professores. Além disso, os surdos estudam em classes com alunos ouvintes, onde o português é ensinado como língua materna, e não como L2 como seria direito desses aprendizes ${ }^{10}$. Nessas condições, os surdos se encontram numa situação precária de acesso ao português, que se agrava de forma aguda para aqueles que estão nos primeiros anos de escolarização, iniciando o processo de alfabetização.

\section{NECESSIDADES E ESPECIFICIDADES DO USUÁRIO E DO APRENDIZ SURDO DE PL2}

Para compreender melhor o processo de ensino-aprendizagem de PL2 para surdos na proposta de educação bilíngue, é importante se conscientizar: (i) das necessidades dos

\footnotetext{
${ }^{9}$ Isso é argumentado pela professora surda Marianne Stumpf (2007, p. 58): “A educação desejável para o aluno surdo, pelo menos no ensino fundamental, é a da classe separada, considerando-se as particularidades da sua aprendizagem e de suas características cognitivas e lingüísticas. A inclusão escolar do aluno surdo numa classe de ouvintes surge como alternativo a não deixá-lo em casa. [...] Os surdos considerando sua forma de comunicação e aprendizagem, pelo menos no nível fundamental, querem classes separadas". $\mathrm{O}$ que se questiona não é a proposta de inclusão educacional e todo seu ideário; a oposição se faz à forma como se tem feito essa inclusão, questionando-se o conceito de que "inclusão" seria estar no mesmo espaço que os outros alunos (LACERDA, 2006).

${ }^{10}$ Nos cursos de capacitação de professores e de intérpretes nos quais atuamos desde 2005, essa era uma discussão frequente, sendo que a responsabilidade pela aprendizagem do surdo nas aulas de português recaía muitas vezes sobre o intérprete, como se a "tradução" de uma aula de língua materna pudesse ser suficiente para transformá-la numa aula de L2.
} 
surdos no que tange ao uso do português escrito; (ii) e das semelhanças que esses aprendizes guardam com outros aprendizes de PL2, ouvintes estrangeiros ou outras minorias linguísticas, como também de suas especificidades, que terão implicações na forma como transcorre o processo de ensino-aprendizagem.

Em relação às necessidades dos surdos, é importante refletir sobre o dia a dia de uma pessoa surda e as necessidades comunicativas que ela encontra no que tange ao uso do português. Em pesquisa em andamento ${ }^{11}$, entrevistamos surdos jovens e adultos, com escolaridade mínima de Ensino Médio incompleto, e perguntamos a eles sobre as práticas linguísticas nas quais usam o português escrito. Pela análise das entrevistas, constatamos que os surdos fazem uso constante de tecnologias de informação e comunicação, especialmente redes sociais como o Facebook e aplicativos de mensagem como o WhatsApp. Por meio dessas tecnologias, esses usuários leem e escrevem vários gêneros textuais, como notícias, divulgação de eventos da área da Libras, mensagens religiosas, etc. Destaca-se, no relato dos surdos, o uso constante de mensagens no dia a dia, seja para manter conversações com amigos ou para resolver questões práticas no trabalho ou em outras esferas da vida social. No âmbito do trabalho, os surdos usam o português escrito para lidar com demandas específicas de cada área de atuação e para enviar e-mails mais formais; já no âmbito escolar, eles usam o português escrito frequentemente para ler e escrever textos escolares/ acadêmicos.

Além dessas práticas de leitura e escrita que também são realizadas por ouvintes, para os usuários surdos, o português escrito assume também a função de apoio em interações face a face em que ocorrem incompreensões. Por exemplo, os surdos relataram que, quando frequentam determinados espaços onde é necessário falar português, e as pessoas não os compreendem, a escrita é utilizada como forma de garantir a compreensão entre os surdos e outras pessoas, tais como atendentes em lojas ou em hospitais, etc.

Esses usos sociais da leitura e da escrita construídos pelos surdos diante das demandas cotidianas precisam ser contemplados nas práticas de ensino de PL2 para surdos. Desta forma, um ensino centrado no uso da língua e no aprendiz pode incorporar: (i) a leitura e produção de gêneros textuais variados conforme as demandas dos alunos;

\footnotetext{
${ }^{11}$ Os dados aqui apresentados fazem parte do seguinte projeto de pesquisa em andamento: SILVA, G. M. da Perfis Linguísticos de Surdos Bilíngues do par Libras-Português. 2015. 22f. Projeto de pesquisa Faculdade de Letras da Universidade Federal de Minas Gerais, UFMG, 2015.
} 
(ii) o uso de tecnologias da informação e comunicação que, de alguma forma, permitem a interação autêntica e quase imediata com outras pessoas; (iii) o uso da língua escrita como apoio nas interações com falantes de português (um tipo de "diálogo escrito"), como forma de contribuir para o desenvolvimento de habilidades comunicativas necessárias à realização ${ }^{12}$ de atividades rotineiras mais simples, como ir a uma loja ou uma lanchonete.

Tendo em vista as necessidades dos surdos, passamos a refletir sobre as semelhanças e diferenças ${ }^{13}$ do aprendiz surdo em relação a um aprendiz ouvinte de PL2. Inicialmente, pode-se dizer que, assim como um aprendiz ouvinte de uma L2, o aprendiz surdo precisa desenvolver a competência lexical, gramatical e comunicativa na nova língua. Além disso, assim como ocorre com o aprendiz ouvinte, a aprendizagem do português como L2 é influenciada por inúmeras questões: o tempo de exposição à língua, a idade do início dessa exposição, a motivação para a aprendizagem, entre outros. Finalmente, é importante destacar que, assim como ocorre com outros aprendizes de L2, os aprendizes surdos são influenciados por sua L1 na aprendizagem de uma L2, ou seja, durante o processo de aquisição de PL2, a Libras vai influenciar os aprendizes na forma como compreendem e usam o português, o que discutiremos mais detidamente adiante ao apresentar características da produção escrita dos surdos.

No tocante às diferenças do aprendiz surdo e do aprendiz ouvinte, começamos indicando a questão da aprendizagem de uma nova modalidade. Para os surdos, não se trata simplesmente de aprender uma L2, mas também de aprender uma segunda modalidade de língua, uma língua oral-auditiva diferente da língua espaço-visual que é sua L1. Um aspecto que precisa ser considerado a esse respeito, por exemplo, é a distância entre as estruturas sintáticas de ambas as línguas. Enquanto a Libras tem uma sintaxe visual, organizada no espaço (QUADROS; KARNOPP, 2004), o português apresenta uma organização linear, cuja aprendizagem é bastante difícil para as pessoas surdas

\footnotetext{
${ }^{12}$ É importante esclarecer que, com essa indicação, não estamos afirmando que o português escrito vai substituir a Libras na interação face a face. O ideal seria que os surdos contassem com intérpretes de Librasportuguês em hospitais e repartições públicas, para se comunicarem com mais segurança e serem efetivamente incluídos nos mais diversos espaços. Porém, em algumas situações mais corriqueiras como compras em lojas, por exemplo, para obter certo grau de autonomia, os surdos podem se comunicar em português escrito e obter êxito nessa comunicação.

${ }^{13}$ Num trabalho anterior (SILVA; GUIMARÃES, 2016), fizemos um levantamento dessas características dos aprendizes surdos e uma reflexão sobre as implicações para o ensino e a produção de materiais didáticos para surdos. Neste artigo, expandimos esse trabalho, comparando aprendizes surdos e ouvintes e discutindo algumas implicações para o processo de ensino-aprendizagem.
} 
(BERNARDINO, 1999; COSTA, 2001). Essa distância estrutural entre as línguas vai se refletir em algumas características da escrita de pessoas surdas.

Além do fato de estarem aprendendo uma nova língua, os aprendizes surdos não irão aprender o português por meio de interações espontâneas mas, sim, na aprendizagem formal na escola (SALLES et al., 2004), iniciada desde o processo de alfabetização. Porém, em níveis mais avançados, os surdos, jovens e adultos, a depender da autonomia e da motivação para aprender português, podem buscar estratégias de aprendizagem mais informais. Para o aprendiz surdo, seja na escola ou fora dela, os textos escritos adquirem o papel importantíssimo de oferecer a ele o insumo da língua já que, apesar de ter contato cotidiano com falantes do português, o surdo não tem acesso pleno ao input oral dessa língua. Nesse caso, é importante que o material didático utilizado seja composto de textos autênticos, sempre que possível, dando representatividade a diversos textos escritos de diferentes esferas sociais, além de cuidar para que a apresentação gráfica do material possa potencializar a aprendizagem visual da escrita pelo aprendiz (SALLES et al., 2004; SILVA; GUIMARÃES, 2016).

Outra especificidade dos aprendizes surdos é que eles fazem parte de uma minoria linguística e cultural, a comunidade surda. Essa comunidade, ao longo dos anos e na interação entre seus membros, vem construindo culturas surdas. Dessa forma, é muito importante que a(s) cultura(s) surda(s) sejam respeitadas e abordadas na aula de PL2 (SILVA, 2008), de forma a oportunizar uma conscientização por parte do aprendiz das diferenças culturais existentes entre surdos e entre surdos e ouvintes. Porém, para esse grupo, como também para outras minorias linguísticas brasileiras, aprender o português não é uma questão de escolha pessoal, mas de necessidade e de direito como cidadãos brasileiros. Isso é algo muito importante para os professores de surdos, pois, ao longo da história, como os surdos foram obrigados a aprender a falar português, muitas vezes a relação deles com a língua majoritária é tensa e precisa ser ressignificada (ver, por exemplo, a análise de QUADROS; PATERNO, 2006). Se o português for ensinado às crianças surdas de forma adequada às suas necessidades e especificidades, a relação com o português pode se transformar e tornar-se uma ferramenta potente para a pessoa surda em várias esferas de sua vida.

Considerando então as características do usuário e aprendiz surdo de PL2 apresentadas até então, passamos abaixo a apresentar algumas especificidades que precisam ser mais bem descritas, dada sua importância para o ensino para esse grupo. 


\title{
Alfabetização e relação visual com a língua escrita
}

No caso dos surdos brasileiros, aprender a ler e a escrever geralmente coincide com aprender uma nova língua, ou seja, os surdos vão iniciar seu processo de alfabetização tendo contato com materiais escritos em português, uma língua "cujo sistema conceitual não corresponde ao sistema de sua L1 e cuja representação gráfica está relacionada à cadeia sonora da língua falada" (SILVA, 2010, p.13). Deste modo, o processo de alfabetização de crianças surdas é altamente complexo, pois envolve o ensino de um sistema de escrita baseado numa correspondência grafofônica a crianças que não tem consciência do som e são falantes de outra língua. Inclusive alguns pesquisadores questionam as consequências cognitivas para as crianças que precisam aprender a ler e escrever numa língua cuja modalidade oral não é plenamente acessível, argumentando a favor da aprendizagem do sistema de escrita de sinais, que vem sendo difundido no Brasil nos últimos anos.

\begin{abstract}
O primeiro problema que deve ser reconhecido é que a escrita alfabética da língua portuguesa no Brasil não serve para representar significação com conceitos elaborados na LIBRAS [...] A língua portuguesa não é a língua natural da criança surda. [...] a língua em que o processo de aquisição da linguagem ocorre naturalmente em crianças surdas brasileiras é a LIBRAS. As línguas de sinais apresentam uma escrita que foi desenvolvida para representar formas e movimentos num espaço definido. [...] Da mesma forma que há alguns anos, os estudos das línguas de sinais revolucionaram a visão quanto à aquisição da linguagem por crianças surdas, o reconhecimento de que as línguas de sinais não são línguas ágrafas transforma a visão do processo de alfabetização dessas crianças. (QUADROS, 1997b, p.74)
\end{abstract}

Entretanto, no Brasil, o sistema de escrita de sinais ainda não é suficientemente difundido, e as crianças surdas vão precisar aprender uma nova língua ao mesmo tempo em que aprendem a ler e escrever, ou seja, “[...] a criança surda brasileira deve 'pular' o rio de um lado para o outro sem ter uma ponte. Assim, a criança vai ser alfabetizada na língua portuguesa sem ter sido "alfabetizada" na língua de sinais." (QUADROS; SCHMIEDT, 2006, p.30). Consequentemente, ensinar uma criança surda a ler e escrever se confunde com ensinar uma L2 - elementos do sistema de escrita devem ser ensinados juntamente com os usos da leitura e da escrita, bem como de aspectos lexicais e estruturais do português. Nesse contexto, a língua de sinais assume o papel importantíssimo de mediar a relação do aprendiz surdo com a língua escrita, conforme argumenta FerreiraBrito (1993, p.74): a "fala será perfeitamente substituível por uma língua de sinais que desempenhará no surdo todas as funções cognitivas necessárias à alfabetização" 
(FERREIRA-BRITO, 1993, p. 74). Ademais, considera-se que a língua escrita apresenta relativa autonomia em relação à fala, como podemos compreender a partir da citação abaixo.

\begin{abstract}
A internalização de significados, conceitos, valores e conhecimentos será realizada através do domínio dessa modalidade de língua [língua de sinais] que servirá como suporte cognitivo para a aprendizagem de um sistema de signos, que, embora organizado a partir da oralidade, guarda características específicas que permite relativa autonomia do sistema que lhe deu origem, permitindo sua apropriação por pessoas surdas que desconhecem o valor sonoro das palavras. Essa relativa autonomia discutida por diversos autores (Faraco, 1991; Ferreira Brito, 1993; Kato, 1987; Sánchez, 1993), nos permite vislumbrar a escrita sob um novo enfoque, divorciada da vinculação inerente mantida com a oralidade [...] (FERNANDES, 1999, p. 66).
\end{abstract}

Por conseguinte, a criança surda vai estabelecer com a língua escrita uma relação visual, como mostram estudos que apontam que crianças surdas, com surdez severa e profunda, não fonetizam a escrita (PEIXOTO, 2006). Muitos pesquisadores têm argumentado sobre essa relação visual estabelecida pelo surdo com a língua escrita, considerando não só o fato de o surdo não ouvir os sons e geralmente não estabelecer relação fonema-grafema, mas discutindo também as consequências cognitivas da surdez relacionadas a uma intensificação do desenvolvimento dos aspectos visuais.

"E se a língua primária for a de sinais, haverá, adicionalmente, uma intensificação de muitos tipos de habilidade visual-cognitiva, tudo acompanhado de uma mudança da predominância do hemisfério direito para a do esquerdo" (SACKS, 1998, p. 123).O pesquisador discute a existência de controvérsias em relação às funções cognitivas dos surdos, mas afirma que há "alguma evidência de que sua intensa visualidade os predispõe para formas de memória e pensamento especificamente "visuais"”.

Tal questão foi abordada por Ferreira-Brito (1993) a qual afirma que "o input gráfico é também visual e que só se atinge verdadeiramente o intelecto da pessoa surda através da visão" (p. 67). Essa autora, tomando como pressuposto a ideia de que uma língua espaço-visual seria a ideal para ser adquirida pela criança surda como L1, afirma que assim como podemos aprender uma língua estrangeira sem saber pronunciá-la, os surdos podem aprender a ler em português sem saber pronunciar essa língua.

Considerando a relação visual estabelecida pelo surdo com a língua escrita, Costa (2001) realizou uma pesquisa com crianças surdas, sendo que um dos objetivos era entender "como percebiam as relações entre significado e significante" (p. 114). Para observar essas relações, a autora realizou uma atividade na qual eram apresentadas 
palavras semelhantes quanto ao significado e quanto aos traços sonoros e gráficos, por exemplo, copo, colo e água. Quando indagadas sobre quais as palavras se pareciam, as crianças surdas respondiam água e copo. Segundo Costa, o desempenho dos alunos indicou que há a primazia do significado sobre o significante, ou seja, os resultados levam a inferir que o que conta para os alunos é a natureza ideográfica da palavra mais do que a alfabética. De acordo com a pesquisadora, Luria havia descrito essa maneira de apreensão da leitura/ escrita sem mediação do som como algo normal. Já para Kato (1987 apud COSTA, 2001), “o que teríamos, então, seria um léxico visual, e não fonológico" (1145). Costa (2001), retomando vários autores que discutem a relação visual da criança surda com a escrita, conclui que esses aprendizes utilizam, em seu processo de aprendizagem da escrita, recursos mais ideográficos que fonográficos (COSTA, 2001, p. 96).

Todas essas reflexões servem para confirmar a relação diferenciada estabelecida pelos surdos com a língua escrita, o que evidencia a urgência da busca de metodologias e estratégias apropriadas para a alfabetização de crianças surdas, tais como: (i) o uso de recursos visuais no processo de ensino-aprendizagem da leitura e da escrita para a criança surda (FERNANDES, 2003); (ii) o estabelecimento da relação entre diferentes signos de forma progressiva - Quadros e Schmiedt (2006, p.42-3) explicam que a leitura para as crianças surdas passam por diferentes níveis, como relacionar palavras com desenhos, palavras com sinais e/ ou com alfabeto manual, etc.; (iii) o uso intenso do alfabeto manual de forma a estabelecer uma ponte entre o sistema de escrita alfabética e a apreensão visual do aluno surdo (LEBEDEFF, 2006, p.145).

\section{A mediação da língua de sinais}

Outra diferença dos surdos que traz importantes implicações é a mediação da LS nos processos de ensino-aprendizagem. Os aprendizes surdos têm a Libras como L1 e usam essa língua como mediadora nos processos de aprendizagem e, como minoria linguística, precisam ter respeitado seu direito de usar essa língua. Esses aprendizes usam o português escrito, mas interagem face a face por meio da LS, inclusive nas aulas de português.

Tal questão fica ainda mais proeminente quando nos tornamos conscientes da centralidade da linguagem nos processos de ensino-aprendizagem, e da importância de uma língua compartilhada entre alunos e professores para um ensino efetivo, que, no caso da maioria dos surdos brasileiros, é a Libras (BOTELHO, 2002; SILVA, 2005; SILVA, 
2010, entre outros). Decorre disso uma primeira implicação que diz respeito à importância de o professor de PL2 ser fluente em Libras, para utilizá-la adequadamente no ensino de português (SILVA; COSTA; LOPES, 2014).

Outra implicação é o contato constante entre essas duas línguas em sala de aula, o que faz com que professores e alunos, em uma turma de surdos, constantemente transitem entre a Libras e o português. Silva (2010), por exemplo, pesquisou uma turma de alunos surdos e professora ouvinte na qual os participantes da turma liam textos escritos em português e falavam sobre o conteúdo do texto em Libras, se engajando, de alguma forma, em atividades de "tradução" desses textos. Porém, transitar entre duas línguas não é algo trivial, e a forma como professor e alunos realizam essas atividades traz implicações para a aprendizagem do português.

Uma questão reportada por Silva (2010) e por outros pesquisadores (BOTELHO, 2002; LODI; HARRISON; CAMPOS, 2002; LEBEDEFF, 2006) é o uso de estratégias de leitura bastante focadas no léxico, em que surdos e professores buscam um sinal para cada palavra, fazendo traduções literais dos textos, o que não contribui para a construção de sentidos pelos aprendizes surdos e também para a aquisição do português escrito, seja do léxico ou da gramática da língua.

Por exemplo, no processo de reconhecimento de vocabulário num texto, é natural que, num primeiro momento, alunos e professor façam uma tradução literal de um dado vocábulo ou mesmo de uma sentença inteira, como uma forma de aproximação inicial do texto. Contudo, não se pode restringir o processo de leitura a esse tipo de leitura palavrasinal; ao contrário, é necessário buscar os sentidos do texto e, para falar sobre esses sentidos, usar a Libras de forma mais natural. Portanto, é importante que professores tenham consciência das diferenças linguísticas entre Libras e português e possam oportunizar aos alunos momentos em que essas diferenças possam ser vislumbradas por eles.

A título de exemplificação, trazemos abaixo um trecho sobre o ensino de leitura para surdos na Suécia, em que se aponta a importância desse trabalho comparativo entre as línguas.

\footnotetext{
A instrução no sueco se afirma na capacidade de o professor trabalhar de maneira contrastiva com ambas as línguas, a língua de sinais e o sueco. $\mathrm{O}$ professor deve ser capaz de transformar o conteúdo dos textos suecos em língua de sinais, explicar elementos nos textos e comparar os meios expressivos de cada língua com a outra. É dessa forma que as crianças surdas aprendem a ler: aprender a ler e aprender a língua sueca se torna um e o mesmo processo (SVARTHOLM, 1999, p.19).
} 
Ligada a essas questões do uso da LS para o trabalho com a língua escrita, surge outra questão de cunho metodológico que não pode ser ignorada. Como fazer a ponte entre o que está escrito no quadro em português e os sinais articulados pelo professor durante a explicação de um texto na aula de leitura ou mesmo de uma estrutura frasal numa aula de gramática? Apontar para o início de uma sentença ou de um trecho do texto não garante que o aluno esteja associando determinadas explicações em Libras a uma palavra específica ou a uma estrutura específica e compreendendo tais elementos de forma a reconhecê-los e compreendê-los em outra ocasião. $\mathrm{O}$ aluno pode estar compreendendo perfeitamente a explicação do professor em Libras, mas pode não estar consciente sobre qual elemento linguístico é objeto da explicação. Sendo assim, é imprescindível criar estratégias visuais em que se criam pontes entre o escrito e o sinalizado (ANDREWS, RUSHER, 2010; SILVA, 2010). Tais estratégias podem envolver formas de marcar visualmente trechos de texto, partes de sentenças ou itens específicos que serão objeto de explicação, e cada professor pode buscar suas próprias estratégias para fazê-lo, como usar diferentes cores para escrever no quadro, sublinhar ou circular trechos, entre outras.

\section{A produção escrita de usuários e aprendizes surdos}

Os aprendizes surdos de PL2, assim como outros aprendizes de L2, muitas vezes vão escrever de forma não convergente com o padrão nativo da língua. Algumas características da produção escrita se devem a influências da L1, no caso dos surdos - a LS, e também ao processo de aprendizagem de uma nova língua, cuja aquisição de regras de funcionamento da língua passa por determinadas etapas e pode ser influenciada por estratégias de ensino.

O primeiro contato com um texto de um surdo pode ser desconcertante se o leitor não conhece a realidade linguística que cerca a surdez (SALLES et al., 2004) e, comumente, alguns profissionais que têm uma visão clínica da surdez, comparam a produção escrita das crianças surdas com a produção de crianças ouvintes (CASTILLA; HOCEVAR; DUHART, 1999). Apesar disso, nos últimos anos, inúmeros trabalhos têmse voltado para a descrição da produção escrita de pessoas surdas: (i) seja em perspectivas mais linguísticas, voltadas à descrição da chamada interlíngua (ALMEIDA, 2007; BROCHADO, 2003, entre outros); (ii) em estudos que se voltam para questões mais amplas, buscando compreender o processo de aquisição da escrita, atrelado ao processo 
de aquisição de L2 (COSTA, 2001); (iii) ou, até mesmo, discutindo-se questões identitárias que cercam a aprendizagem da escrita (FERNANDES, 1999).

Costa (2001), por exemplo, analisou a presença de construções do tipo tópicocomentário na escrita de crianças surdas (ver exemplo 1), construção essa presente em Libras. Constatando a influência da Libras na escrita, essa autora argumentou a favor de um ensino mais contextual da língua de forma a possibilitar a aquisição do português pelas crianças. Já Almeida (2007) analisou o uso de flexão verbal do português pelos surdos e constatou que os surdos usam predominantemente verbos no infinitivo, indicando a variação temporal por outros recursos, como advérbios ou outros itens lexicais.

(1) Bilhete da pesquisadora para o aluno: Márcio, o que você gosta de fazer Resposta do aluno: Pipa tem gosta

Todavia, é importante esclarecer e discutir não somente como a Libras influencia a escrita das pessoas surdas, mas como outros fatores também entram em cena nesse processo, como as estratégias de ensino empregadas ${ }^{14}$. Essa reflexão sobre as características da escrita da pessoa surda é importante para que o professor possa avaliálo de forma adequada, respeitando as etapas de aquisição do português pelo aprendiz, mas também se comprometendo no ensino efetivo do português para os surdos.

Recorremos à reflexão proposta por Leal (2005) sobre a produção de texto na escola no caso de crianças ouvintes e propomos também que o diálogo, o contrato ético entre os sujeitos e o respeito mútuo sejam a base para a avaliação de textos escritos por surdos, "evitando atitudes radicais que vão do tudo marcar ao nada marcar" (p.65). Muitos profissionais têm, em nome do respeito ao texto do surdo e a sua condição linguística, mantido esses sujeitos no "não saber que não sabem", negando a eles o direito de se apropriarem do português, como instrumento de conquista de seus direitos e de exercício da cidadania, como denuncia Fernandes (1999):

Diante disso, acreditamos ser muito genéricas as afirmações, correntes no meio escolar, de que devemos considerar na língua portuguesa, no caso dos surdos, apenas o conteúdo em detrimento da forma; que deva se avaliar sua

\footnotetext{
${ }^{14}$ Plaza-Pust (2008 apud PLAZA-PUST, 2014), por exemplo, analisando a aquisição do alemão por surdos usuários da língua de sinais alemã sugere que práticas de ensino focadas numa determinada estrutura frasal podem influenciar a forma como os aprendizes surdos adquirem a gramática da língua escrita.
} 
competência lingüística e não seu desempenho. Tais generalizações podem levar a atos extremos de arbitrariedade, nos quais, pela falta de conhecimento em relação ao que realmente acontece nas produções escritas, se considere qualquer tipo de produção como aceitável. Esta forma de avaliação, que ignora qualquer critério, é tão danosa para a educação do surdo como as práticas tradicionais, até então desenvolvidas, que desconsideravam seu conhecimento anterior como ponto de partida para a aprendizagem (FERNANDES, 1999, p. 77).

Em relação às implicações para a prática pedagógica, podemos então dizer que a correção de textos de aprendizes surdos deve partir do conhecimento, por parte do professor, das fases de aquisição do PL2 pelo surdo, sendo que o professor não deve corrigir certos tipos de construção que ainda não foram adquiridas. No entanto, esse mesmo professor, a partir desse conhecimento, pode e deve construir atividades que levem o aluno a pensar sobre a estrutura linguística do português e seus significados, de forma condizente com as etapas de aquisição de PL2 pelos surdos, fazendo uma conexão entre uso da língua e reflexão sobre ela.

\section{CONSIDERAÇÕES FINAIS}

Alguns aspectos relativos à condição dos surdos como usuários e aprendizes de PL2 não podem passar despercebidos como procuramos mostrar ao longo deste artigo. Resumimos aqui dois pontos que consideramos de extrema relevância: primeiramente, salientamos a importância do uso da Libras no processo de ensino-aprendizagem de PL2, o que aponta para a necessidade de professores fluentes e para o direito de os surdos usarem livremente a Libras para se relacionar com o português escrito.

Em segundo lugar, ressaltamos a necessidade de uma ressignificação do português como a L2 $\underline{\text { da }}$ comunidade surda, em termos de direito de usar essa língua de forma autônoma e aprendê-la por meio de metodologias específicas, que considerem as especificidades dos aprendizes surdos, tais como a relação visual estabelecida com a língua escrita, sua condição de minoria linguística, as necessidades comunicativas no uso cotidiano da leitura e da escrita, entre outras. A situação linguística vivenciada pelas pessoas surdas é bastante complexa, e a escola não pode se furtar da responsabilidade de oportunizar aos surdos, como direito, uma aprendizagem significativa do português para o uso social dessa língua de forma autônoma. 
As pesquisas e práticas relacionadas ao ensino de PL2 para surdos têm ganhado muito com o intercâmbio com a área de ensino de português para falantes de outras línguas nos últimos anos, mas é preciso avançar no desenvolvimento de novas propostas e estratégias de ensino adequadas a esses aprendizes. Assim, enfatizamos a importância do desenvolvimento de pesquisas na área para que o ensino de PL2 para surdos possa realmente responder às necessidades e anseios da comunidade surda.

\section{REFERENCIAS}

ALMEIDA, J. A. de. Aquisição do Sistema Verbal do Português-por-escrito pelos Surdos. Dissertação (Mestrado) - Universidade de Brasília, Brasília, 2007.

ANDREWS, J. F.; RUSHER, M. Codeswitching Techniques: evidence-based instructional practices for the ASL/English Bilingual classroom. American Annals of the Deaf, v.155, n.4, pp.407-424, 2010.

BERNARDINO, E. L. A construção da referência por surdos na Libras e no português escrito: a lógica do absurdo. Dissertação (Mestrado em Estudos Linguísticos) - Faculdade de Letras, Universidade Federal de Minas Gerais, Belo Horizonte, 1999.

BOTELHO, P. Linguagem e Letramento na Educação de Surdos: ideologias e práticas pedagógicas. Belo Horizonte: Autêntica, 2002.

BRASIL. Parâmetros Curriculares Nacionais: $3^{\circ}$ e $4^{\circ}$ ciclos do Ensino Fundamental: Língua Portuguesa. Brasília/DF: MEC/SEF, 1998.

BRASIL. Lei $n$. 10.436, de 24 de abril de 2002. Dispõe sobre a Língua Brasileira de Sinais - Libras e dá outras providências. Distrito Federal, Brasília, 2002. Disponível em: <http://www.planalto.gov.br/ccivil_03/LEIS/2002/L10436.htm>. Acesso em: 31 jan. 2013.

BRASIL. Decreto $n^{o}$ 5.626, de 22 de dezembro de 2005. In: BRASIL. Presidência da República. Presidência da República Federativa do Brasil. 2005.

BRASIL. Ministério da Educação. Secretaria de Alfabetização e Diversidade. Relatório sobre a Política Linguística de Educação Bilíngue - Língua Brasileira de Sinais e Língua Portuguesa do Grupo de Trabalho, designado pelas Portarias no 1.060/2013 e n 91/2013 do MEC/SECADI. Brasília, fevereiro de 2014. Disponível em: <http://www.bibliotecadigital.unicamp.br/document/?code=56513 $>$.

BROCHADO, S. M. D. A apropriação da escrita por crianças surdas usuárias da língua de sinais brasileira. Tese (Doutorado) - Universidade Estadual Paulista, Faculdade de Ciências e Letras de Assis, 2003. Disponível em: 〈http://hdl.handle.net/11449/102476>.

CASTILLA, M. E.; HOCEVAR, S. O. de; DUHART, S. M. Adquisición de la lectura y escritura em niños sordos em escuela bilíngüe. In: SKLIAR, C. (org.). Atualidade da Educação Bilíngüe para Surdos. $2^{a}$ ed. Porto Alegre: Mediação, 1999. 2 v. Pp. 83-94. 
COSTA, D. A. F. A apropriação da escrita por crianças e adolescentes surdos: interação entre fatores contextuais, L1 e L2 na busca de um bilingüismo funcional. Tese (Doutorado). Faculdade de Letras, Universidade Federal de Minas Gerais, Belo Horizonte, 2001.

FERNANDES, S. É possível ser surdo em português? Língua de sinais e escrita: em busca de uma aproximação. In: SKLIAR, C. (org.). Atualidade da Educação Bilíngüe para Surdos. $2^{a}$ ed. Porto Alegre: Mediação, 1999. 2 v. Pp. 59-82.

FERREIRA-BRITO, L. F. Integração social \& educação de surdos. Rio de Janeiro: Babel, 1993.

GROSJEAN, F. Studying Bilinguals. New York: Oxford University Press, 2008.

HOFFMEISTER, R. J. Famílias, crianças surdas, o mundo dos surdos e os profissionais da audiologia. In: SKLIAR, C. (org.). Atualidade da Educação Bilíngüe para Surdos. $2^{\mathrm{a}}$ ed. Porto Alegre: Mediação, 1999. 2 v. Pp. 113-207.

HOFFMEISTER, R. J. A Piece of the Puzzle: ASL and comprehension in Deaf Children. In: CHAMBERLAIN, C.; MORFORD, J. P.; MAYBERRY, R. R. (Ed.) Language Acquisition by Eye. Mahwah, N.J: Lawrence Erlbaum Associates, 2000. Pp. 143-163.

LACERDA, C. B. F. de. A Inclusão Escolar de Alunos Surdos: o que dizem alunos, professores e intérpretes sobre esta experiência. Cad. Cedes, v. 26, n. 69, pp. 163-184, maio/ago. 2006.

LEAL, L. F. V. A formação do Produtor de Texto Escrito na Escola: uma análise das relações entre os processos interlocutivos e os processos de ensino. In: ROCHA, G.; VAL, M. G. C. Reflexões sobre Práticas Escolares de Produção de Texto: o sujeito-autor. Belo Horizonte: Autêntica/ Ceale/ FaE/ UFMG, 2005. Pp. 53-68.

LEBEDEFF, T.B. Análise das estratégias e recursos "surdos" utilizados por uma professora surda para o Ensino de Língua escrita. Perspectiva, v. 24, n. 3, pp. 139-152, 2006.

LODI, A. C. B.; HARRISON, K. M. P.; CAMPOS, S. R. L. Letramento e Surdez: um olhar sobre as particularidades dentro do contexto educacional. In: LODI, A. C. B., HARRISON, K. M. P., CAMPOS, S. R. L., TESKE, O. (orgs). Letramento e Minorias. Porto Alegre: Mediação, 2002. Pp. 35-46.

MAYBERRY, R. I. When timing is everything: Age of first-language acquisition effects on second-language learning. Applied Psycholinguistics, v. 28, n.3, pp. 537-549, 2007.

PLAZA-PUST, C. Deaf education and bilingualism. In: PFAU, R.; STEINBACH, M.; WOLL, B. (Eds.). Sign Language: An International Handbook. Berlin, Germany: De Gruyter Mouton, 2012. Pp.949-979

PLAZA-PUST, C. Language Development and Language Interaction in Sign Bilingual Language Acquisition. In: MARSCHARK, M.; KNOORS, H.; TANG, G. Bilingualism 
and Bilingual Deaf Education. Oxford/NewYork: Oxford University Press, 2014. Pp 2354.

PEIXOTO, R. C. Algumas considerações sobre a interface entre a Língua Brasileira de Sinais (LIBRAS) e a Língua Portuguesa na construção inicial da escrita pela criança surda. Cad. Cedes, v. 26, n. 69, pp. 205-229, maio/ago. 2006.

PEREIRA, M. C. C. Papel da língua de sinais na aquisição da escrita por estudantes surdos. In: LODI, A. C. B.; HARRISON, K. M. P.; CAMPOS, S. R. L.; TESKE, O. (orgs). Letramento e Minorias. Porto Alegre: Mediação, 2002. Pp. 47-55.

PEREIRA, M. C. C. O ensino de português como segunda língua para surdos: princípios teóricos e metodológicos. Educar em Revista, Edição Especial n. 2/2014, pp. 143-157, 2014.

QUADROS, R. M. de. Educação de surdos: a aquisição da linguagem. Porto Alegre: Artes Médicas, 1997a.

QUADROS, R. M. de. Aquisição de L1 e L2: o contexto da pessoa surda. In: Seminário Desafios e Possibilidades na Educação Bilíngue para Surdos, jul. 1997, Rio de Janeiro. Anais... Rio de Janeiro: INES, Divisão de Estudos e Pesquisas - Rio de Janeiro: Ed. Líttera Maciel Ltda, 1997b, pp.70-87.

QUADROS, R. M.; CRUZ, C. R. Língua de Sinais: Instrumentos de Avaliação. Porto Alegre: Artmed, 2011.

QUADROS, R. M. de; KARNOPP, L. Língua de sinais brasileira: estudos lingüísticos. Porto Alegre, Artes Médicas, 2004.

QUADROS, R. M. de; SCHMIEDT, M. L. P. Idéias para ensinar português para alunos surdos. Brasília: MEC, SEESP, 2006.

QUADROS, R. M.; PATERNO, U. Políticas linguísticas: o impacto do decreto 5626 para os surdos brasileiros. Espaço: informativo técnico-científico do INES, Rio de Janeiro, n. 25, pp.19-25. 2006.

SACKS, O. Vendo vozes: uma viagem ao mundo dos surdos. Tradução Laura Teixeira Motta. São Paulo: Companhia das Letras,1998.

SALLES, H. M. M. L. et al. Ensino de Língua Portuguesa para Surdos: caminhos para a prática pedagógica. Brasília: MEC, SEESP, 2004.

SECRETARIA MUNICIPAL DE EDUCAÇÃO DE SÃO PAULO/ DIRETORIA DE ORIENTAÇÃO TÉCNICA. Orientações curriculares e proposição de expectativas de aprendizagem para Educação Infantil e Ensino Fundamental: Língua Portuguesa para pessoa surda / Secretaria Municipal de Educação - São Paulo : SME / DOT, 2008.

SILVA, G. M. Lendo e Sinalizando Textos: uma análise etnográfica das práticas de leitura em português de uma turma de alunos surdos. Dissertação (Mestrado em Educação) Faculdade de Educação, Universidade Federal de Minas Gerais, Belo Horizonte, 2010. 
SILVA, G. M. da; COSTA, J. M. da, LOPES, L. P. S. Formação de Professores de Português para Surdos: entre o ideal, o real e o possível. Caminhos em Linguística Aplicada, v.11, n. 2, pp.01- 23, 2014.

SILVA, G. M. da; GUIMARÃES, A. B. C. Materiais didáticos para o ensino de português como segunda língua para surdos: uma proposta para o nível básico. Trabalho apresentado no V Encontro Mundial sobre o Ensino de Português, 2016, Berkeley (Califórnia, EUA).

SILVA, I. As representações do surdo na escola e na família: entre a (in)visibilização da diferença e da "deficiência". Tese (Doutorado em Linguística Aplicada) - Instituto de Estudos da Linguagem, Universidade Estadual de Campinas. Campinas, 2005.

SILVA, S. G. de L. da. Ensino de Língua Portuguesa para Surdos: das políticas as práticas pedagógicas. Dissertação (Mestrado em Educação) - Universidade Federal de Santa Catarina. Florianópolis, 2008.

SKLIAR, C. Uma perspectiva sócio-histórica sobre a psicologia e a educação dos surdos. In: SKLIAR, C. (org.). Educação e Exclusão: abordagens sócio-antropológicas em educação especial. Porto Alegre: Mediação, 1997. Pp. 75-110.

STUMPF, M. R. Pedagogia surda no contexto cotidiano da inclusão: espaços, prática e políticas dentro e fora. In: $2^{\circ}$ SEMINÁRIO NACIONAL DE PEDAGOGIA SURDA, $n^{\circ} 2$, 2007, Vitória, ES. Anais do $2^{\circ}$ Seminário Nacional de Pedagogia Surda: Educação de Surdos: Práticas Pedagógicas e Políticas Educacionais. Anais... Vitória: UFES, Centro de Educação, 2007. Pp.51-62.

SVARTHOLM, K. Bilingüismo dos Surdos. In: SKLIAR, C. (org.). Atualidade da Educação Bilíngue para Surdos. 2ª ed. Porto Alegre: Mediação, 1999. Pp.15-23. 